\title{
EFEK INHALASI AROMATERAPI LEMON, JAHE DAN KOMBINASI TERHADAP FREKUENSI MUAL MUNTAH PADA IBU HAMIL TRIMESTER I
}

\author{
Miskiyah Tamar'), Irna Nursanti ${ }^{2)}$, Natsir Nugroho ${ }^{3)}$ \\ ${ }^{1}$ Mahasiswi, Program Magister Keperawatan FIK Universitas Muhammadiyah Jakarta, \\ STIKes Muhammadiyah Palembang \\ ${ }^{2,3}$ Dosen, Program Magister Keperawatan FIK Uiversitas Muhammadiyah Jakarta \\ E-mail: miskiyahtamar1986@gmail.com
}

\begin{abstract}
The pregnancy period in a woman's body experiences many changes or adaptations due to fetal growth needs. Various adaptations during pregnancy are adaptations of physiology to the digestive system, endocrine system and adaptations of psychology. Nausea vomiting are normal in pregnancy which occurs around 50-90\% of pregnant women experience nausea in the first trimester. Nausea vomiting in pregnant women will be better if it is able to overcome the problem of nausea in early pregnancy by using non-pharmacological supplementary therapy. Nonpharmacological therapy is non-instructive, non-invasive, inexpensive, simple, effective, and without adverse side effects. Non-pharmacological therapy can be done by giving aromatherapy. The purpose of this study is to prove the comparison between the lemon, ginger and combination aromatherapy inhalation intervention to decrease nausea and vomiting in pregnant women in the first trimester. The design of this study used Quasi Experiment Pre-Post Test Design. The number of research samples for each group is 10 respondents.The purposive sampling research technique.The measuring instrument used a standard questionnaireRhodes INVR.Data analysis using Wilcoxon test and Kruskal Wallis test. The results showed that there were differences in the Mean rank before and after aromatherapy lemon inhalation interventions, inhalation of ginger aromatherapy, and combination against the frequency of nausea vomiting in pregnant women in the first trimester. The highest pre-post mean rank is the combination of aromatherapy inhalation interventions is 17,60 and post 18.20. It can be concluded that combination intervention is more effective in reducing nausea and vomiting in first trimester pregnant women.
\end{abstract}

Keywords: Lemon aromatherapy, Ginger aromatherapy, Nausea vomitingin first Trimester

\section{PENDAhUluan}

Peristiwa kehamilan dianggap sebagai suatu krisis maturasi atau suatu periode transisi dalam siklus kehidupan seorang wanita. Peristiwa ini menyebabkan seorang wanita mengalami berbagai perubahan besar dalam kehidupannya. Selama periode kehamilan tubuh wanita mengalami banyak perubahan atau adaptasi sehubungan dengan kebutuhan pertumbuhan janin. Berbagai adaptasi pada masa kehamilan yaitu adaptasi fisiologi maupun psikologi (Indriyani, 2013).

Adaptasi fisiologi meliputi pengaturan sistem endokrin melalui mekanisme hormonal menimbulkan berbagai adaptasi pada tubuh wanita hamil sebagai respon terhadap kehidupan janin (Indriyani, 2013).

Adaptasi psikologi yang terjadi pada ibu hamil trimester pertama sering dianggap sebagai periode penyesuaian. Penyesuaian yang dilakukan ibu adalah menghadapi kenyataan bahwa ia sedang hamil, sebagian ibu merasa sedih dan ambivalen tentang kehamilannya dan perasaan yang tidak nyaman disebabkan oleh adanya rasa mual dan muntah dan perubahan selera makan (Hutahaean, 2013).

"Morning Sickness" merupakan keluhan mual (nausea) dan muntah (emesis gravidarum) adalah gejala yang wajar dan sering kedapatan pada kehamilan trimester pertama. Disebut morning sickness karena biasanya terjadi pada pagi hari, namun tidak selalu timbul pada pagi hari. Rata- rata wanita hamil mulai mengalami morning sickness pada minggu ke 4 atau ke 6 . Namun jika mual dan muntah tesebut makin berat, maka dapat menyebabkan gangguan kehamilan yang disebut hiperemis gravidarum (Indriyani, 2013). 
Penyebab mual muntah pada ibu hamil masih belum diketahui dengan pasti tetapi ada berbagai hal yang menjadi faktor predisposisi seperti faktor psikologis dan perubahan hormon. Wanita hamil dengan tipe kepribadian histeris dan ketergantungan yang berlebihan pada ibu cenderung mengalami mual dan muntah. Faktor lain yang berpengaruh adalah hormon progesteron dan HCG yang menyebabkan peningkatan motililitas lambung serta asam lambung sehingga sehingga timbul reaksi mual muntah (Quinlan, 2003 dalam Saswita, 2011).

Mual dan muntah pada kehamilan mempengaruhi kenyamanan wanita hamil karena itu dapat dikaitakan dengan teori kenyamanan yang diperkenalkan oleh Katharine Kolcaba.. Kolcaba menjelaskan bahwa rasa nyaman merupakan pengalaman yang holistik dan memberikan kekuatan ketika seseorang membutuhkannya yang terdiri dari tiga bentuk kenyamanan (Relief, Ease, dan Transcendence) dalam empat konteks (fisik, psikospiritual, lingkungan dan sosiokultural) (Alligood, 2017).

\section{Struktur Taksonomi Kolcaba}

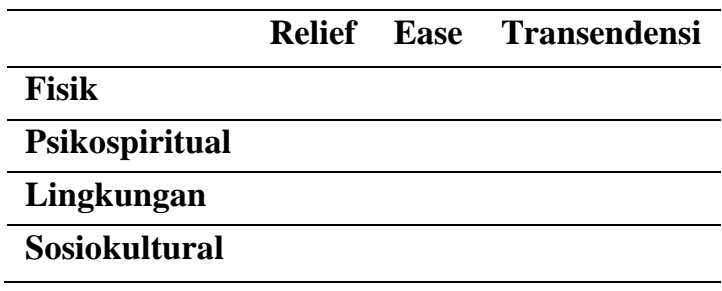

Mual muntah pada ibu hamil akan lebih baik jika mampu mengatasi masalah mual pada awal kehamilan dengan menggunakan terapi pelengkap non farmakologi. Terapi nonfarmakologi bersifat noninstruktif, noninfasif, murah, sederhana, efektif, dan tanpa efek samping yang merugikan. Terapi nonfarmakologi dapat dilakukan pemberian aromaterapi (Wiknjosastro, 2010 dalam Rahayu, 2018).

Aromaterapi merupakan terapi modalitas atau pengobatan alternative dengan menggunakan sari tumbuhan aromaterapi murni berupa bahan cairan tanaman yang mudah menguap dan senyawa aromaterapi lain dari tumbuhan. Aromaterapi dapat digunakan sebagai solusi untuk mengatasi mual muntah pada ibu hamil trimester pertama adalah aromaterapi lemon, jahe, lavender, papermint (Rahayu, 2018).

Lemon minyak esensial (citrus lemon) adalah salah satu yang paling banyak digunakan minyak herbal dalam kehamilan dan dianggap sebagai obat yang aman pada kehamilan. Menurut sebuah studi, 40\% wanita telah menggunakan aroma lemon untuk meredaan mual dan muntah, dan 26,5\% dari mereka telah dilaporkan sebagai cara yang efektif untuk mengontrol gejala mual muntah pada ibu hamil trimester I (Maternity, 2017).

Sedangkan Jahe sebagai salah satu jenis tanaham herbal mempunyai banyak keunggulan dibandingkan dengan tanaman herbal lain, khususnya bagi ibu hamil yang sedang mengalami mual muntah. Keunggulan pertama jahe adalah kandungan mengandung minyak terbang (minyak atsiri) yang menyegarkan dan memblokir reflek muntah (Nikita, 2011 dalam Rahayu, 2018).

\section{METODE}

Desain penelitian ini adalah quasi experiment dengan rancangan penelitian prepost test design. Variabel independen dalam penelitian ini adalah inhalasi aromaterapi lemon, inhalasi aromaterapi jahe, dan kombinasi, dan variabel dependen dalam penelitian ini adalah frekuensi mual muntah yang diukur menggunakan kuesioner Rhodes INVR sebelum dan sesudah dilakukan intervensi inhalasi aromaterapi.

Sampel dalam penelitian ini adalah sebanyak 10 responden tiap kelompok intervensi, jadi besar sampel penelitian untuk 3 kelompok adalah 30 responden. Teknik pengambilan sampel dalam penelitian ini menggunakan teknik non probability sampling yaitu purposive sampling. Kriteria inklusi dalam penelitian ini, yaitu sebagai berikut: Ibu hamil trimester I yang mengalami mual muntah yang tidak sedang menjalani terapi farmakologi, Ibu hamil yang bersedia menjadi responden.

Peneliti memilih responden dan memberikan kebebasan kepada responden, apabila responden bersedia peneliti memberikan lembar persetujuan untuk menjadi responden dan menjaga kerahasiaan dengan tidak mencantumkan nama responden.

Responden yang terpilih akan dikelompokkan menjadi 3 kelompok. 
Kelompok satu ibu hamil trimester I dengan mual muntah diberikan intervensi inhalasi aromaterapi lemon. Kelompok dua ibu hamil trimester I dengan mual muntah diberikan intervensi inhalasi aromaterapi jahe. Kelompok tiga ibu hamil trimester I dengan mual muntah diberikah intervensi kombinasi. Ketiga kelompok akan mengisi kuesioner sebelum dan sesudah dilakukan intervensi dan setiap responden akan mendapatkan lembar observasi untuk menghitung frekuensi mual muntah yang di rasakan selama menjalani intervensi inhalasi aromaterapi selama 4 hari.

Analisa data menggunakan analisis univariat dan bivariat. Perbedaan mean sebelum dan sesudah intervensi menggunakan uji Wilcoxon. Sedangkan uji statistik yang digunakan untuk melihat perbedaan mean antara kelompok intervensi menggunakan uji Kruskal Wallis.

\section{HASIL DAN PEMBAHASAN}

Analisa univariat dalam hasil penelitian ini menunjukkan bahwa (tabel 1) karakteristik ibu hamil trimester I yang mengalami mual muntah. Variabel numerik adalah usia dan variabel kategorik adalah agama, paritas, pendidikan, pekerjaan dan suku. didapatkan bahwa Ibu hamil yang mual dan muntah diketahui bahwa responden dengan usia terbanyak adalah kelompok usia 20-35 tahun sebanyak 28 orang $(93,3 \%)$ dengan nilai mean 27,40 dan usia minimum 19 tahun dan maksimum 35 tahun. Paritas terbanyak ada pada kelompok multipara sebanyak 20 orang (63,7\%). Responden dengan pendidikan terbanyak ada pada kelompok pendidikan SMA sebanyak 15 orang $(50 \%)$. Diketahui bahwa lebih banyak yang tidak bekerjasebanyak 20 orang $(63,7 \%)$ dan sebagian besar responden sukunya adalah sumatera sebanyak 26 orang $(86,7 \%)$.

Analisa bivariat dalam penelitian ini menggunakan uji Wilcoxon karena data berdistribusi tidak normal dan setelah itu dilakkukan uji Kruskal Wallis untuk melihat perbedaan mean antara kelompok intervensi. Berdasarkan hasil analisis data yang tertera (table 2) hasil uji Wilcoxon menunjukkan perbandingan frekuensi mual dan muntah pada kelompok intervensi inhalasi aromaterapi lemon sebelum dan sesudah intervensi diperoleh nilai signifikan 0,042 ( $\mathrm{p}$ $<$ 0,05), kelompok intervensi inhalasi aromaterapi jahe sebelum dan sesudah intervensi. Diperoleh nilai signifikan 0,113 (p $<0,05)$, kelompok intervensi kombinasi sebelum dan sesudah intervensi diperoleh nilai signifikan 0,440 ( $\mathrm{p}<0,05)$. Berdasarkan hasil analisis data yang tertera (table 3 ) hasil uji Kruskal Wallis menunjukkan diperoleh nilai sebelum intervensi dari ketiga kelompok dengan $p=0,375$ dan nilai sesudah intervensi dari ketiga kelompok dengan $\mathrm{p}=0,439$. Oleh karena nilai $\mathrm{p}>0,05$, maka dapat disimpulkan tidak terdapat perbedaan antara ketiga kelompok.

Tabel 1: Karakteristik Responden

\begin{tabular}{llccc}
\hline Variabel & \multicolumn{1}{c}{ Kategorik } & $\mathbf{N}$ & $\%$ & $\begin{array}{c}\text { Uji Homogenitas } \\
\text { p value }\end{array}$ \\
\hline Usia & $<20$ Tahun & 2 & 6,7 & 0,296 \\
& $20-35$ tahu & 28 & 93,3 & \\
& Mean & 27,40 & & \\
& Median & 25,50 & & - \\
& SD & 5,137 & & \\
& Min - Max & $19-35$ & & 0,004 \\
& Muslim & 30 & 100 & \\
\hline Agama & Non Muslim & 0 & & \\
& & & & \\
& Primigravida & 10 & 33,3 & \\
& Multigravida & 20 & 63,7 & \\
\hline Pendidikan & SD & 4 & 13,3 & \\
& SMP & 8 & 26,7 & \\
\hline
\end{tabular}




\begin{tabular}{llccc}
\hline & SMA & 15 & 50 & \\
& $\begin{array}{l}\text { Perguruan } \\
\text { Tinggi }\end{array}$ & 3 & 10 & \\
& & & & 0,660 \\
\hline Pekerjaan & Bekerja & 10 & 33,3 & \\
& Tidak bekerja & 20 & 63,7 & 0,028 \\
& Sumatera & 26 & 86,7 & \\
& Bukan sumatera & 4 & 13,3 & \\
& & & & \\
\hline
\end{tabular}

Tabel 2: Perbedaan Sebelum dan Sesudah Intervensi

\begin{tabular}{lccc}
\hline \multicolumn{1}{c}{ Jenis kelompok } & $\mathbf{N}$ & $\begin{array}{c}\text { Median } \\
\text { (min-max) }\end{array}$ & p value \\
\hline $\begin{array}{l}\text { Inhalasi aromaterapi lemon } \\
\text { Sebelum }\end{array}$ & 10 & $10(3-12)$ & 0,042 \\
Sesudah & 10 & $5(0-10)$ & \\
\hline Inhalasi aromaterapi jahe & & & \\
$\begin{array}{l}\text { Sebelum } \\
\text { Sesudah }\end{array}$ & 10 & $11,5(4-14)$ & 0,113 \\
\hline $\begin{array}{l}\text { Inhalasi aromaterapi } \\
\text { kombinasi (lemon dan jahe) }\end{array}$ & 10 & $3(0-19)$ & \\
$\begin{array}{l}\text { Sebelum } \\
\text { Sesudah }\end{array}$ & 10 & $11(5-20)$ & 0,440 \\
\hline
\end{tabular}

Tabel 3: Perbedaan Sebelum dan Sesudah Antara Kelompok Intervensi

\begin{tabular}{clcc}
\hline \multicolumn{1}{c}{ Pengukuran } & \multicolumn{1}{c}{ Jenis Kelompok } & Mean Rank & p value \\
\hline \multirow{2}{*}{ Pre Test } & $\begin{array}{l}\text { Inhalasi aromaterapi } \\
\text { lemon }\end{array}$ & 16,50 & 0.375 \\
& $\begin{array}{l}\text { Inhalasi aromaterapi } \\
\text { jahe }\end{array}$ & 12,40 & \\
& $\begin{array}{l}\text { Inhalasi aromaterapi } \\
\text { kombinasi (lemon dan } \\
\text { jahe) }\end{array}$ & 17,60 & \\
\hline \multirow{2}{*}{ Post Test } & $\begin{array}{l}\text { Inhalasi aromaterapi } \\
\text { lemon } \\
\text { Inhalasi aromaterapi } \\
\text { jahe } \\
\text { Inhalasi aromaterapi } \\
\text { kombinasi (lemon dan } \\
\text { jahe) }\end{array}$ & 13,35 & 0.439 \\
& 18,95 & \\
& & \\
\hline
\end{tabular}

Dalam penelitian ini usia responden pada Ibu Hamil trimester I yang mengalami mual muntah berusia pada rentang 20 sampai 35 tahun. Menurut BKKBN RI (2017), usia ideal perempuan untuk menikah dan melahirkan adalah pada usia minimal 21 tahun.

Status paritas responden ibu hamil trimester I yang mengalami mual muntah sebagian besar multigravida. Menurut 
Saifuddin (2010) Mual dan muntah terjadi pada $60-80 \%$ primigravida dan $40-60 \%$ terjadi pada multigravida. (Maternity, 2016).

Tingkat pendidikan pada ibu hamil trimester I yang mengalami mual muntah dalam penelitian sebagian besar adalah SMA. Menurut Rahmawati 2010 dalam Rahayu 2018, pendidikan dapat mempengaruhi seseorang termasuk juga perilaku terhadap pola hidup dalam memotivasi untuk siap berperan serta dalam perubahan kesehatan.

Hasil penelitian sebagian besar responden tidak bekerja yaitu 20 responden $(63,7 \%)$. Ibu hamil dengan status tidak bekerja dan bekerja akan mengalami gejala mual muntah dikarenakan pengaruh hormon $\mathrm{HCG}$ yang tinggi.

Sedangkan suku terbanyak adalah Sumatera dimana mual muntah juga dipengaruhi oleh suku atau budaya mulai dari bahan makanan yang di makan ibu hamil, sebagian besar jenis masakannya adalah karbohidrat dan mengandung lemak dengan nilai asam lemak jenuh, sehingga ibu hamil memiliki risiko lebih besar untuk mengalami kejadian mual muntah.

\section{Inhalasi Aromaterapi Lemon}

Hasil penelitian membuktikan bahwa ada perbedaan mean antara sebelum dan sesudah jawaban kuesioner pada intervensi inhalasi aromaterapi lemon. disimpulkan bahwa ada pengaruh intervensi inhalasi aromaterapi lemon terhadap mual dan muntah pada ibu hamil trimester I dengan nilai $\mathrm{p}$ value $0,042(\mathrm{p}<0,05)$.

Dalam penelitian Yavari kia $\mathrm{P}$ et al (2014), bahwa Aroma lemon bisa efektif dalam mengurangi mual dan muntah kehamilan ( $p<0,001$ dan $p=0,049)$. Sejalan juga dengan hasil penelitian Astriana (2015) dalam penelitiannya bahwa ada pengaruh lemon inhalasi aromatherapi terhadap mual pada kelompok ibu hamil dengan nilai $\mathrm{p}$ value $0.000<0.05$.

Menurut teori yang dikemukan oleh Tiran (2009) Mual dan muntah selama kehamilan biasanya disebabkan oleh tingginya fluktasi kadar HCG (human chorionic gonadotrophin), khususnya karena periode mual muntah gestasional yang paling umum adalah pada 12-16 minggu pertama, yang pada saat itu HCG mencapai kadar tinggi.
Menurut analisis peneliti bahwa inhalasi aromaterapi lemon dapat menurunkan mual muntah secara fisiologis. Ibu hamil akan mengalami banyak perubahan atau adaptasi selama kehamilan.

\section{Inhalasi Aromaterapi Jahe}

Hasil penelitian membuktikan bahwa ada perbedaan mean antara sebelum dan sesudah jawaban kuesioner pada intervensi inhalasi aromaterapi jahe. Dapat disimpulkan bahwa tidak ada pengaruh intervensi inhalasi aromaterapi jahe terhadap mual dan muntah pada ibu hamil trimester I karna nilai $\mathrm{p}$ value $0,113(\mathrm{p}<0,05)$.

Sebuah studi yang dilakukan oleh Meltzer (2000) dipublikasikan dalam American Journal of Obstetric and Gynecology (2001) menemukan bahwa jahe sangat membantu dalam mengurangi morning sickness (Saswita, 2011).

Dalam penelitian Kartikasari (2018), hasilnya menunjukkan bahwa ada pengaruh pemberian aromaterapi jahe terhadap intensitas mual dan muntah pada ibu hamil dengan Hyperemesis Gravidarum.

Menurut analisis peneliti inhalasi aromaterapi jahe dapat menurunkan mual muntah secara fisiologis. Ibu hamil akan mengalami banyak perubahan atau adaptasi selama kehamilan, dimana ibu hamil akan mengalami ketidaknyaman pada perubahan tersebut.

\section{Kombinasi}

Hasil penelitian membuktikan bahwa ada perbedaan mean antara sebelum dan sesudah jawaban kuesioner pada intervensi inhalasi aromaterapi kombinasi, maka dapat disimpulkan bahwa tidak ada pengaruh intervensi inhalasi aromaterapi kombinasi terhadap mual dan muntah pada ibu hamil trimester I karna nilai $\mathrm{p}$ value 0,440 ( $\mathrm{p}<$ $0,05)$.

Penelitian ini menggabungkan kedua intervensi yang diberikan yaitu intervensi inhalasi aromaterapi lemon dan inhalasi aromaterapi jahe. Peneliti memberikan aromaterapi lemon dan aromaterapi jahe kepada responden. Kemudian mengajarkan responden tentang inhalasi aromaterapi kombinasi. Meneteskan 2-3 tetes aromaterapi lemon atau jahe ke tisu lalu menghirupnya dengan 3 kali pernapasan setelah itu istirahat 
dalam waktu 5 menit, selanjutnya teteskan kembali aromaterapi lemon atau jahe 2-3 teses ke tisu yang lain dan hirup dengan 3 kali pernapasan.

Menurut analisis peneliti intervensi kombinasi dapat menurunkan mual muntah secara fisiologis. Aromaterapi lemon dan jahe mengandung minyak herbal yang dalam kehamilan dianggap sebagai obat nonfarmakologi yang aman pada untuk meredaan atau menurunkan mual dan muntah yang fisiologis terjadi pada masa kehamilan trimester I.

\section{Perbedaan antara kelompok intervensi}

Hasil penelitian terbukti bahwa perbedaan dari ketiga intervensi adalah intervensi kombinasi lebih efektif. Pada tabel 3, mean sebelum dan sesudah intervensi inhalasi kombinasi yaitu inhalasi aromaterapi lemon dan inhalasi aromaterapi jahe adalah 17,60 dan 18,20 , artinya bahwa mean mual dan muntah paling tinggi adalah inhalasi aromaterapi kombinasi.

\section{KESIMPULAN}

Pemberian intervensi inhalasi aromaterapi kombinasi lebih efektif dan berpengaruh dalam mengurangi frekuensi mual muntah pada ibu hamil trimester I di Puskesmas Taman Bacaan Palembang.

Diharapkan institusi pelayanan kesehatan dapat menjadikan penelitian ini sebagai data dasar dengan menyarankan intervensi inhalasi aromaterapi lemon dan inhalasi aromaterapi jahe kepada ibu hamil trimester 1 yang mengalami mual dan muntah.

\section{REFERENSI}

Aligood, Martha Raile. (2017). Pakar Teori Keperawatan dan karya mereka, edisi Indonesia ke delapan Volume 2. Singapore: Elsevier

Astriana, dkk. (2015). Pengaruh Lemon Inhalasi Aromatheraphy Terhadap Mual Pada Kehamilan di BPS Varia Mega Lestari S.ST., M.Kes Batupuru Kecamatan Natar Kabupaten Lampung Selatan Tahun 2015. Jurnal Kebidanan. Vol. 1. No. 3, Oktober 2015: 143-147. Diakses Tanggal 16 September 2018.
BKKBN RI. (2017). Stop Ibu Hamil di Atas Usia 35. Diakses Tanggal 14 Juli 2019.

Hutahaean, Serri. (2013). Perawatan Antenatal. Jakarta: Salemba Medika

Indriyani, Diyan. (2013). Keperawatan Maternitas Pada Area Perawatan Antenatal. Yogyakarta: Graha Ilmu.

Kartikasari, Ikke Systyanti, dkk. (2018) PengaruhAromaterapiJaheTerhadapIntensita sMual Dan MuntahPadaIbuHamilDengan Hyperemesis Gravidarum Di PuskesmasNgemplakBoyolaly. Diakses tanggal 25 Juli 2019

Maternity D, Sari D Y, dan Manjorang M U. (2016). Pengaruh Inhalasi Aromaterapi Lemon Terhadap Morning Sickness Pada Ibu Hamil Di Wilayah Kerja Puskesmas Tulang Bawang I Kecamatan Banjar Agung Kabupaten Tulang Bawang Tahun 2016. Jurnal Kebidanan Vol.2 no.3. Diakses tanggal 24 Desember 2018

Maternity D, Putri Ariska P, dan Sari D Y. (2017). Inhalasi Lemon Mengurangi Mual Muntah Pada Ibu Hamil Trimester Satu. Universitas Malahayati Fakultas Kedokteran. Jurnal Ilmiah Bidan. Vol. II. No. 3. Diakses Tanggal 14 Oktober 2018

Rahayu. (2018). Efektifitas Pemberian Aromaterapi Lavender dan Jahe Terhadap Penurunan Frekuensi Mual Muntah Pada Ibu Hamil Trimester I di BPM Trucuk Klaten. Jurnal Kebidanan dan Kesehatan Tradisional, Volume 3. No. 1. Maret 2018, hlm 1-56. Diakses Tanggal 11 Oktober 2018.

Saswita, dkk. (2011). Efektifitas Minuman Jalie dalam Mengurangi Emesis Gravidarum pada Ibu Hamil Trimester I. Jumal Ners Indonesia, V o 1 . 1, No. 2, Maret 2011. Diakses Tanggal 21 Juli 2019.

Tiran. (2009). Mual dan Muntah Kehamilan. Jakarta: EGC

Yavari kia P et al.(2014). The Effect of Lemon Inhalation Aromatherapy on Nausea and Vomiting of Pregnancy: A Double-Blinded, Randomized, Controlled Clinical Trial. Iran 
Red Crescent Med Journal: 16(3): e14360.

Diakses Tanggal 05 April 2018. 